\title{
Comparative physiology of Malpighian tubules: form and function
}

\author{
This article was published in the following Dove Press journal: \\ Open Access Insect Physiology \\ 21 April 2016 \\ Number of times this article has been viewed
}

\section{Roberta CF Nocelli' \\ Priscila Cintra-Socolowski ${ }^{2}$ \\ Thaisa C Roat ${ }^{2}$ \\ Elaine CM Silva-Zacarin ${ }^{3}$ \\ Osmar Malaspina ${ }^{2}$}

'Department of Nature Sciences, Mathematics and Education (DCNME), Center of Agronomic Sciences (CCA), UFSCar, Universidade Federal de São Carlos Campus Araras, Sao Paulo, SP, Brazil; '2Department of Biology, Center of Studies of Social Insects, UNESP-Universidade Estadual Paulista, Rio Claro, SP, Brazil; ${ }^{3}$ Department of Biology (DBio-CCHB), UFSCar, Universidade Federal de São Carlos Campus Sorocaba, Sao Paulo, SP, Brazil

Correspondence: Priscila CintraSocolowski

Department of Biology, Center of Studies of Social Insects, UNESP-Universidade Estadual Paulista, Av. 24-A, I5I5, CEP 13506-900, Rio Claro, SP, Brazil Fax +551935264284 Email priscilacintra@yahoo.com.br
Abstract: Malpighian tubules (MTs) are the main osmoregulatory and excretory organs of insects and are considered analogous to the nephridia or kidneys, the corresponding organs of annelids and the vertebrates. MTs are responsible for the production of an isosmotic filtrate from hemolymph, the primary urine, which carries excretory products of metabolism and toxic compounds into the hindgut. The MTs of Drosophila (Diptera), the more representative studied insect, develop from the hindgut primordium and visceral mesoderm. Once formed, tubules in Diptera can grow in size to answer the increasing demands on osmotic and ionic regulation and renal clearance. However, there are up to 30 million species of insects occupying several ecological niches; therefore we can conclude that our models of transport and control of MTs cannot be generalistic. In this synthetic review, morphological and ultrastructural figures from hymenoptera, such as bees and ants, have been provided to illustrate the MTs from other insect groups. These organs have been widely used in ecotoxicological studies, as they quickly respond to changes in the insect's environment, and the tubules induce detoxification genes. The large number of scientific manuscripts around the world indicates that the MTs can be used for evaluation of biomarkers, detoxification, innate immunity, and as models for human renal diseases. Other studies have suggested that stem cells and progenitor cells may be involved in the repair and regeneration of injured renal tissue. Considering the different habitats of all organisms that have MTs, we can expect that the new techniques available for sequencing DNA and mRNA and the development of the omic-sciences, with the imminent sequencing of multiple insect genomes, will provide new data and further elucidate the different mechanisms by which MTs perform their functions.

Keywords: morphology, ultrastructure, embryonic origin, control, osmoregulatory, excretory

\section{Introduction}

All multicellular organisms have a specialized organ to concentrate and excrete waste from the body. The transporting tubules in these excretory systems are similar in a diversity of animals, including insects and mammals. In insects, Malpighian tubules (MTs) are the main osmoregulatory and excretory organs and are considered analogous to the nephridia of annelids or the kidneys of vertebrates. ${ }^{1-3}$ In addition to osmoregulation, the MTs are also involved in the transport of organic substances, the body's defense system, and chemical detoxification processes. ${ }^{4}$

The passage from an aquatic environment to terrestrial habitats resulted in a change in the excretion system from a process of elimination to a water conservation system. In addition to water, this system must also control levels of electrolytes and other molecules, ${ }^{5}$ functions that can be seen in the kidneys in vertebrates and the MTs in 
Drosophila. These vastly different animals share some similar characteristic features during renal tubular development. ${ }^{6}$

Vertebrate kidneys are derived through the mutual induction of the ureteric bud and metanephric mesoderm, and have the capacity to recover and regenerate following episodes of acute injury. The MTs of Drosophila, however, develop from the hindgut primordium and visceral mesoderm. Previous studies have suggested that stem cells and progenitor cells may be involved in the repair and regeneration of injured renal tissue. ${ }^{7}$

Morphologically, MTs are thin fingerlike extensions connected to the intestinal tract between the midgut and the posterior gut or hindgut (Figure 1).

In most cases, the MTs are free in the body cavity; however, some insects have a cryptonephridial complex where the distal end of these tubules is held in contact to the rectal wall by the perinephric membrane. ${ }^{8}$ This arrangement is present in most larval Lepidoptera and Neuroptera, in some Symphyta and Diptera larvae, and in many larvae and adults of Coleoptera. ${ }^{9}$
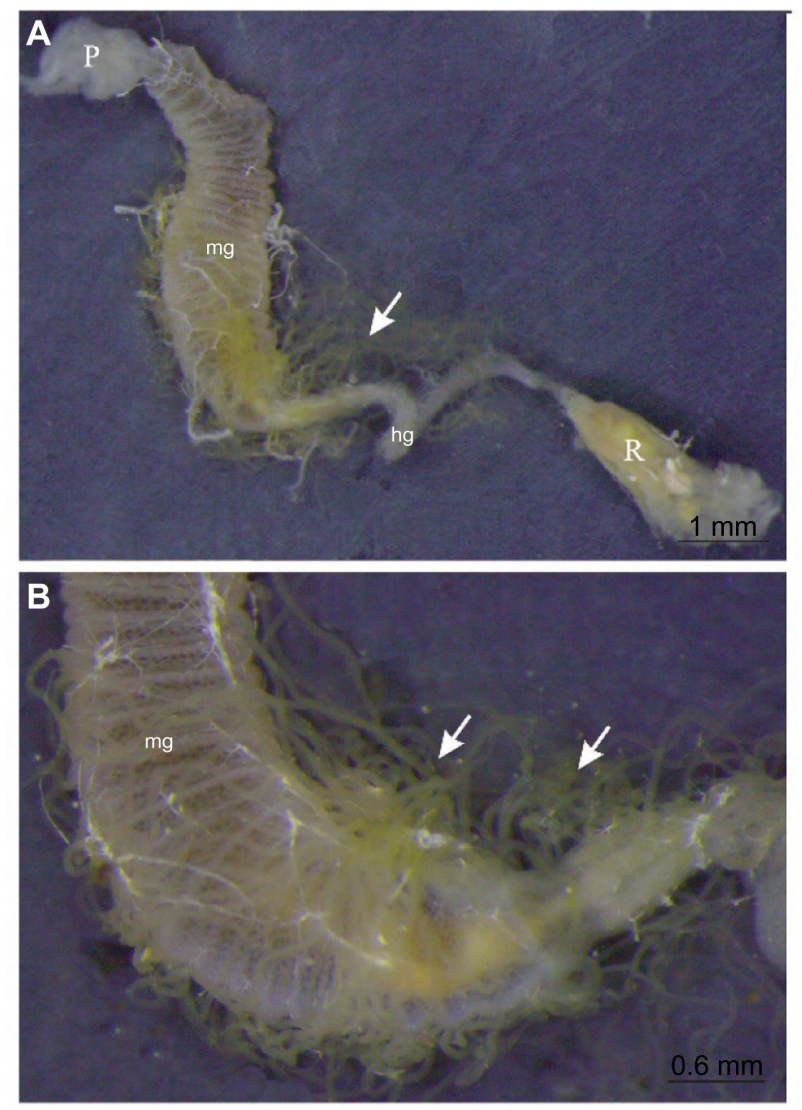

Figure I Digestive tract of Apis mellifera adult worker.

Notes: (A) Anatomical view of digestive tract showing insertion of Malpighian tubules (arrow) between the $\mathrm{mg}$ and the hg. (B) Details of Malpighian tubules (arrows) (Photos courtesy of Pamela Decio).

Abbreviations: $\mathrm{R}$, rectum; $\mathrm{mg}$, midgut; hg, hindgut; $\mathrm{P}$, proventriculus.
MTs produce the primary urine, an isosmotic filtrate from the hemolymph, which carries excretory products of metabolism and toxic compounds into the hindgut. The final phase of the excretory process commonly occurs in the rectum, from which some ions and water are reabsorbed. ${ }^{10}$ Excretion occurs by secretion of ions and organic molecules from the hemolymph into the lumen of the tubule. From the lumen, the contents are modified as they pass through the MT and hindgut until they are excreted.

\section{Embryonic origin and larval period}

The osmotic and ionic regulation of larvae is functionally carried out by MTs, and is developed early in the insect embryo, before feeding begins. ${ }^{11}$ Tubulogenesis requires the integration and coordination of various cellular events such as cell division, cell migration, cell intercalation, and cell shape changes. ${ }^{12}$ This process leads to the formation of elongated structures, variable in number, formed by a monolayer epithelium that can be composed of one or two cell types.

These processes are well described for Drosophila, where four tubules originate from the hindgut primordium. In order to achieve the final morphology, some developmental phases are distinguished: cell specification, the eversion of the tubule primordia from the hindgut, 2-5 rounds of cell division, cellular rearrangement with tubular elongation, positioning in the body cavity, differentiation and polarization of the stellate cells, and, finally, cell differentiation of the physiologically active cells with the appearance of uric acid in the tubule lumen. ${ }^{12}$ Once formed, tubules in Diptera can grow in size to meet increasing demands on osmotic and ionic regulation and renal clearance. ${ }^{12}$

During the larval stage of bees (Figure 2), the products absorbed from the hemolymph by MTs are accumulated in their lumen until the end of the larval feeding phase (Figure 2A). The MTs finally excrete their accumulated products when there is a connection between the midgut and the hindgut preceding metamorphosis (Figure 2B). ${ }^{13}$

At the end of the larval stage of bees, MTs become inoperative and begin their degenerative process (Figure $2 \mathrm{C}$ ). During metamorphosis of bees, new MTs differentiate from stem cells located at the insertion of the tubules into the digestive tract. ${ }^{13}$

The physiological demand of insects must increase the excretory load of MTs because they grow through successive larval instars. Because of this, insect MTs have two modes of development, the enlargement by cell growth of a few tubules (established early in embryogenesis) or the 

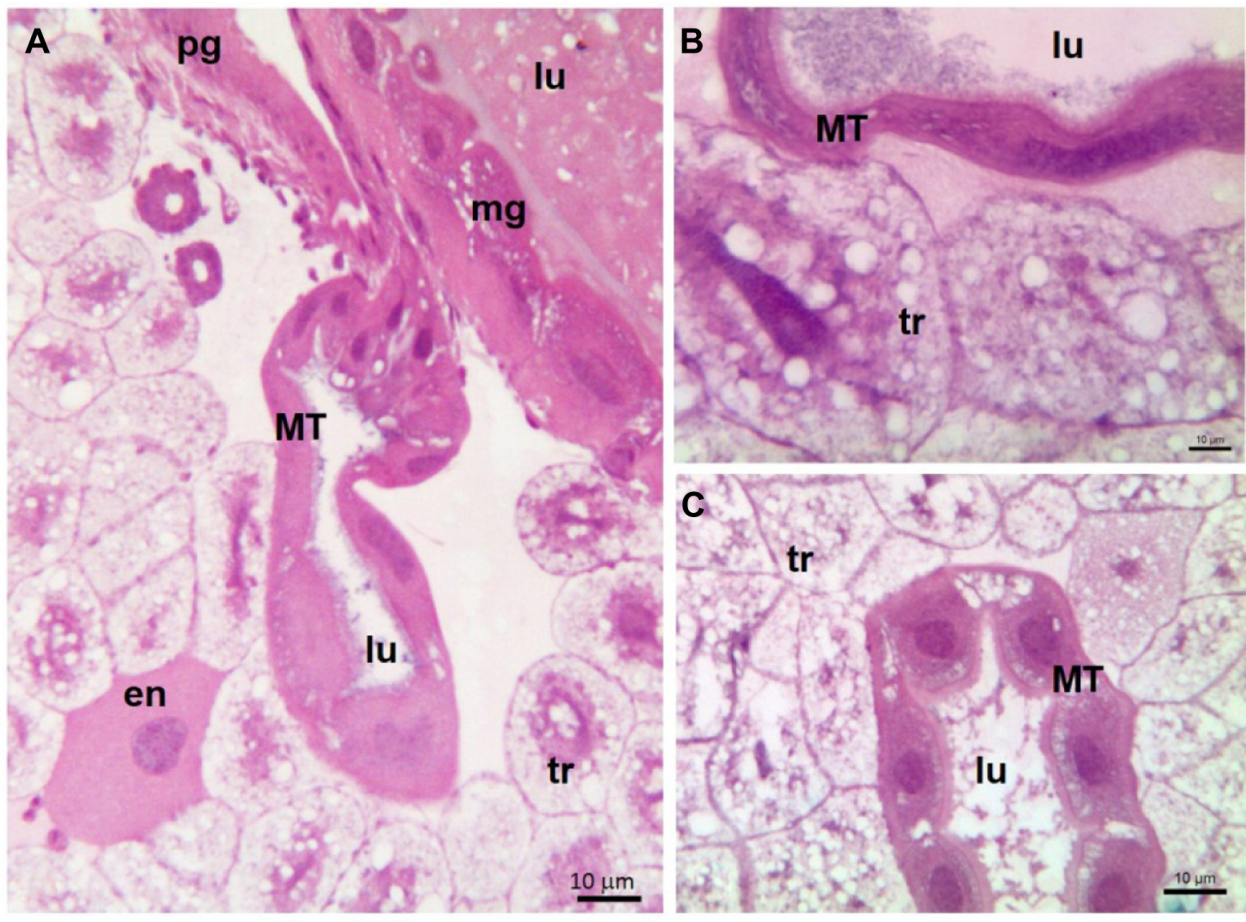

Figure 2 MT of Apis mellifera larvae; Histological sections stained with hematoxylin-eosin.

Notes: (A) End of the larval feeding phase showing the MTs connected to transition between the mg and the pg. (B) Distal portion of the MTs with flattened cells and larger lu containing excretory products. (C) Proximal portion of MTs during the end of larval postdefecation phase showing vacuolization of the epithelium of the tubule. Abbreviations: MT, malpighian tubule; mg, midgut; pg, posterior gut; lu, lumen; tr, trophocyte of fat body; en, oenocyte of fat body.

production of new tubules according to the number of instars. For this reason, adult insects have many tubules compared with young stages, but the tubules are relatively small if there are more than $200 .^{3}$

Cruz-Landim and Rodrigues ${ }^{14}$ studied seven species of Melipona (Hymenoptera, Apidae) to correlate the length of the MTs with the species weight and the original environment. They demonstrated that the lengths of the MTs of bees from dry environments differ from those from semihumid and humid environments. They also showed that the rectal pads, responsible for absorption of the water available in the rectum, are smaller in bees from semihumid environments when compared with bees that inhabit humid environments. Silva-de-Moraes and Cruz-Landim ${ }^{15}$ demonstrated that larvae of Melipona quadrifasciata anthidioides Lepeletier have eight long MTs that degenerate in the prepupae stage. The nuclei of the MTs cells become irregular, and the cells are reabsorbed. MTs in bees are highly variable in number and size among species and life stages, but the causes of this variability are still unknown. ${ }^{16}$

Insects without a pupal stage (hemimetabolous insects) and holometabolous insects, which have a pupal stage, retain their MTs throughout metamorphosis, ${ }^{17}$ while in the larval stage of bees, tubules degenerate and new tubules are formed at the end of metamorphosis to work in the adult stage. In species with no destruction of the MTs during metamorphosis, such as Drosophila melanogaster, apoptotic genes are activated but can assume other functions such as directing the rearrangement of the adult tubule. However, the actual function of these genes in tubulogenesis is unclear. ${ }^{18}$

In adult insects, MTs vary in number, with just 5 in workers of Crematogaster lineolata and Myrmicina americana (Hymenoptera, Myrmicinae) ${ }^{19}$ and 250 in Schistocerca gregaria (Orthoptera, Acrididae). For social insects, the number of tubules varies between 4 and 64, depending on the species and the developmental stage. ${ }^{13}$

Among ant species, MTs exhibit great diversity in number, size, morphology, and arrangement. ${ }^{20}$ In ants of the tribe Cephalotini (Cephalotes atratus, C. clypeatus, and C. pusillus) (Hymenoptera, Formicidae), six MTs with a free distal end are present in the body cavity, and all studied species present the same excretory pattern. ${ }^{21}$

\section{Morphology}

The MTs consist of a single layer of one or more types of cells, surrounding a blind-ending lumen (Figure 3). According to insect groups, tubules are divided into distinct regions, 


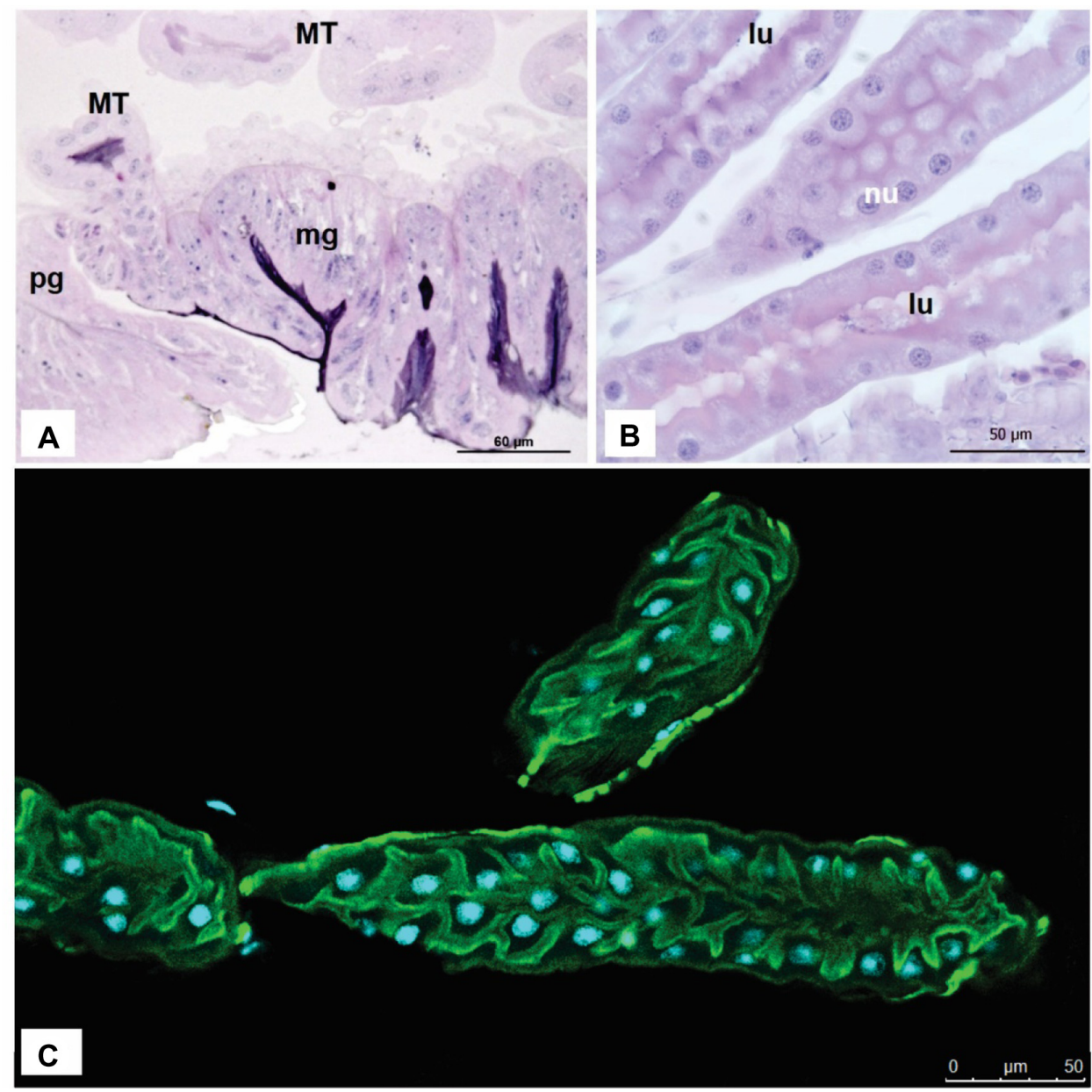

Figure 3 MTs of adult worker Apis mellifera; Histological sections stained with Hematoxylin-Eosin.

Notes: (A) MTs connected between the $\mathrm{mg}$ and pg. (B) Details of MTs showing epithelium with nu cells surrounding the lu. (C) Whole mount preparation of MT of Melipona scutellaris (Hymenoptera, Apidae) worker. Confocal images with faloidin showing F-actin in green (Cy5) and nuclei in cyan (DAPI).

Abbreviations: MT, Malpighian tubule; mg, midgut; pg, posterior gut; nu, mononucleated; lu, lumen.

according to function and morphology. Histologically, the MTs possess pyramidal or cubical cells, with nuclei in the center or the base containing 1-3 nucleoli. In these species, the transitional portion between the midgut and the ileum (pylorus) is closed on one side by the pyloric valve, and on the other by a glandular epithelium, the MTs being empty in this region. ${ }^{21}$ In MTs of Solenopsis saevissima (Hymenoptera, Formicidae), three segments were distinguished: proximal, middle, and distal, and this distinction is based on the shape and structure of the epithelial cells lining the different segments of the tubules. ${ }^{22}$ However, this regionalization is not observed in Bombus morio, where the epithelium has two cell types that are interspersed throughout the tubule. ${ }^{23}$

The ultrastructure of the cells is variable throughout the species. In Musca domestica (Diptera), ${ }^{24}$ Frankliniella occidentalis (Thysanoptera), ${ }^{25}$ and Calpodes ethlius (Lepidoptera), ${ }^{26}$ the MT layer is uniform, while, in other insects, it can be observed in different cell types, functionally and morphologically. ${ }^{3,9,23}$ In adults, MTs are composed of two cell types: the principal cells and the stellate cells, which play different roles in the process of excretion. ${ }^{12}$

Malpighian tubules of the yellow fever mosquito differ morphologically from other epithelia in two ways: the abundance of intracellular concretions (metallo-organic aggregates of $\mathrm{Ca}^{2+}, \mathrm{Mg}^{2+}$, and $\mathrm{K}^{+}$) in principal cells and the presence of a long slender mitochondrion in every microvillus of the apical brush border. ${ }^{27}$

The intracellular concretions in the MTs of ants can be visualized as granules containing electron-dense concentric rings (Figure 4). According to some authors, these granules consist of metabolic remnants of filtrates from the hemolymph and indicate that cells with high metabolic activity store large quantities of granules. These granules are characteristic not only of ant and other insect MTs but also some cells of the midgut epithelium. ${ }^{28}$ 

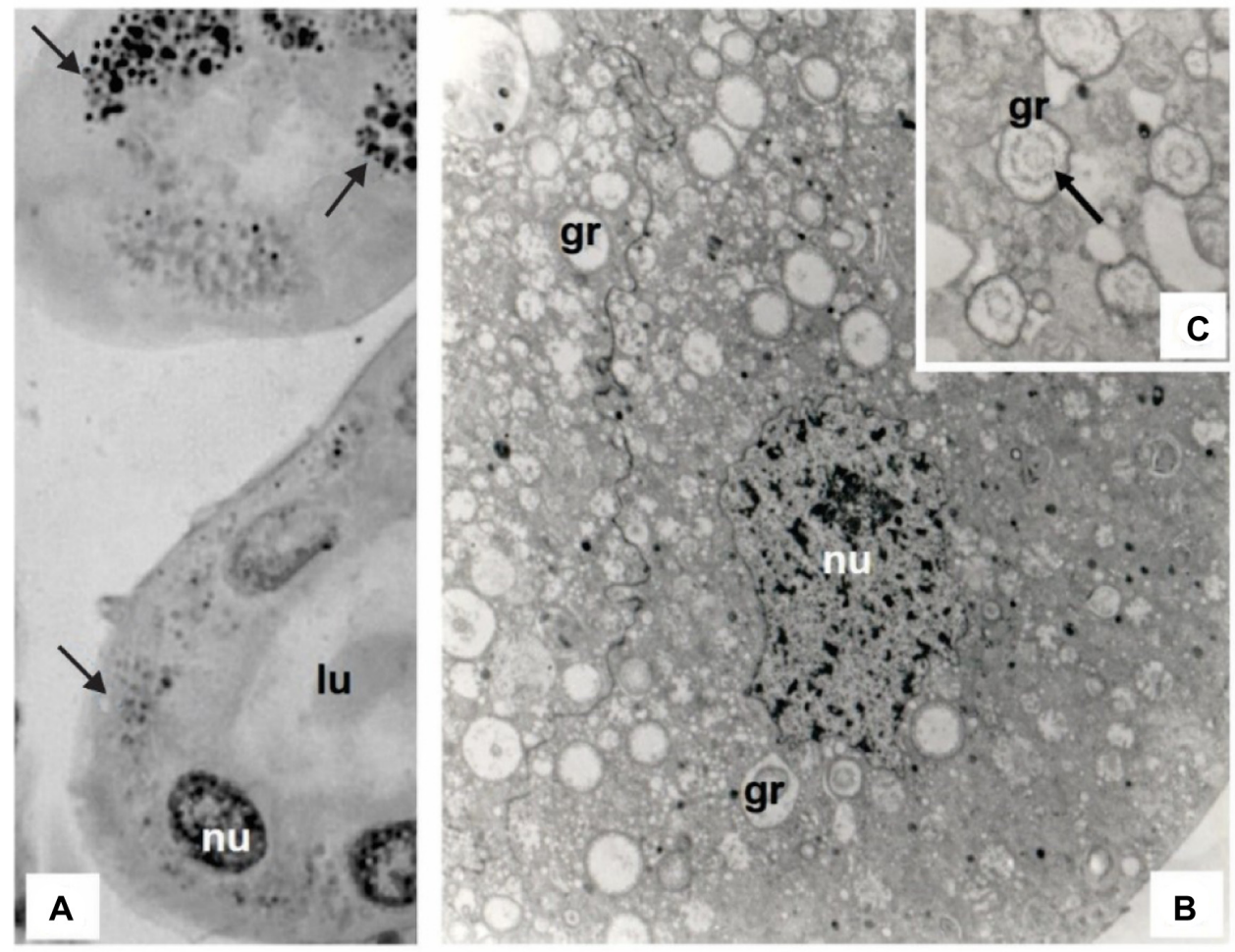

Figure 4 MT of an adult worker Atta sexdens rubropilosa.

Notes: (A) Histological sections stained with hematoxylin-eosin. Note the granules (black arrows) spread by the cytoplasm of excretory cells. (B and C) Transmission electron microscopy. General view of excretory cell in (B) highlighting the gr and nu. Detail of granules in (C) showing the concentric ring (black arrow) inside them.

Abbreviations: MT, Malpighian tubule; nu, nucleus; lu, lumen; gr, granules.

The walls of the MTs are composed of a single layer of cuboidal epithelial cells (Figures 2-4). These cells rely on active transport mechanisms to concentrate organic molecules and ions in the lumen. They form an excellent system in which it is possible to evaluate and study some of the properties of secretion in a transporting epithelium. ${ }^{29}$

The ultrastructure of the MT epithelium can vary among insects, but the basic features are similar. Thus, the apical surfaces of the MT epithelium possess microvilli of varying descriptions, depending on the cell type. ${ }^{30}$ The basal portion of the epithelium has invaginations in its plasma membrane that are perpendicular to the basal lamina and that externally cover the epithelium. Excretory cells have mitochondria, Golgi complexes, and granular and agranular endoplasmic reticulum. Most of the mitochondria are associated with basal membrane invaginations that indicate the energetic need of the transport process of material from the hemolymph to the tubule epithelium.

In Bombus morio, however, type I cells have mitochondria associated with both: the apical microvilli and the invaginations of the basal plasma membrane, indicating a specialized epithelium in active transport of fluids and ions, which assume the role of the rectal pads, absent in this insect. Type
II cells are more related to the selective endocytosis, because they show a little amount of mitochondria associated with an apical membrane with shorter and irregular projections. ${ }^{23}$

In many insects, the Malpighian cells are polytene, and the nuclei of the cells are large. ${ }^{9}$ In Dinoponera australis, organs related to digestion and excretion present the much higher levels of endopolyploidy when compared with other organs such as brain and muscle. ${ }^{31}$ This was also observed in Apis mellifera by Rangel et al, ${ }^{32}$ although no statistically significant differences were observed. In addition to differences with regard to other organs, in Apis mellifera, MT showed higher ploidy values in an age-dependent manner. The higher ploidy in this organ may be related to their function, they result in a core-shape and larger volumes that may have higher rates of gene expression, increasing their metabolic capacity.

In a large number of insect species, various types of intracellular crystals can be found. The organic and inorganic composition of intracellular crystals determines the color of the tubules. The transport properties of the cells are determined by many factors that control their activity besides their position in the membranes. ${ }^{9}$ These crystals are always associated with a specific cell type, such as the upper tubule cells of Rhodnius prolixus or the primary cell of Aedes 
taeniorhynchus and Periplaneta americana. ${ }^{33}$ However, in Bombus morio, the two cell types I and II have crystals in their cytoplasm crystals. ${ }^{23}$ These crystals are generally supposed to serve as a form of storage excretion, and the most common are the "laminate spheres" or spherocrystals, which have unclear origin. ${ }^{34}$

\section{Physiology}

The transport system in the tubules of excretory systems of insects and mammals are similar, although they differ among species and at various developmental stages within the same species. Although they are important for different metabolic processes in various animal groups, nitrogen compounds need to be excreted. The main compounds that are finally excreted are ammonia, urea and uric acid. MTs, as well as the renal tubules of vertebrate, actively secrete uric acid.

In addition to the excretion of nitrogenated metabolites, MTs are involved in insect homeostasis, intestinal $\mathrm{pH}$, regulation and secretion of calcium, ${ }^{35}$ immunological defense, and clearance of toxic substances. ${ }^{11}$ MTs also provide minerals that are stored in the form of spherites, important for crickets in the hibernation period, ${ }^{36}$ or supply substances for symbiotic microorganisms in the midgut ${ }^{37}$ and regulate lipid production in ants. ${ }^{10}$

Confirming the role of the MTs as the major excretory system in the insect, they can act as a quality controller for the hemolymph. There are several genes that are abundant, or highly enriched in the MTs from Drosophila, which participate in metabolism and detoxification, such as the genes that express functions of enzymes Type III alcohol dehydrogenase, Alcohol dehydrogenase, Glutathione transferase, and Cytochrome P450. Several cytochrome P450s are heavily enriched in the tubules, and most of them are of the Cyp6 class, which is insect-specific. ${ }^{38}$ Glutathione transferases play a role in phase II metabolism of xenobiotics, conjugating reduced glutathione to lipophilic substrates, making them more hydrophilic, and thus more easily excreted. The insecticide resistance is directly attributable to overexpression of cytochrome $\mathrm{P} 450^{39}$ or glutathione-S-transferase. ${ }^{40}$ These findings suggest the possibility of the MTs being an important site in determining insecticide resistance.

In the mammalian kidney, most of the contents of the kidney tubule derive from plasma filtered into the lumen at Bowman's capsule. In insects, excretion is performed by transporting organic molecules and ions from the hemolymph into the lumen of the MT. As in the mammalian kidney, however, the contents of the lumen are modified as they pass through the MTs and hindgut. ${ }^{29}$
The excretory system of insects, in general, is considered to be divided into two parts: the primary urine is formed through secretion by the MTs, and the final excreta content is defined by reabsorption in the rectum. Fluid secretion is driven by the active transport of cations, and potassium chloride is the predominant solute in the tubule fluid. However, the concentrations of other solutes, such as sodium, sugars, and amino acids, are relatively low in the hemolymph. The MTs are also capable of actively secreting toxic substances, such as cardiac glycosides. ${ }^{35}$

In insects, there is no glomerular filtration, and in the MTs, tubular secretion is the only mechanism for presenting solute and water to the tubule lumen. Therefore, the renal turnover of the extracellular fluid compartment is accomplished by the epithelial transport mechanisms, such as secretion and absorption. The distal segment of the MT (blind-ended) secretes water, organic solutes, and electrolytes, and the proximal segments reabsorb solute and water. ${ }^{41-45}$ Reabsorption then continues in the hindgut and rectum. ${ }^{46,47}$

The primary urine has a high $\mathrm{K}^{+}$and a low $\mathrm{Na}^{+}$concentration, relative to their concentrations in the hemolymph. ${ }^{48}$ The potassium transference from the hemolymph to the lumen occurs against the concentration gradient and requires energy by active transport (ATPase). The urine is iso-osmotic with the hemolymph, and its osmolarity is not dependent on the urine flow rate. Complementarily, there is a difference in the tubular wall electric potential: the inner sides are generally 20-30 mV positive..$^{11,41,49}$

Several studies evidence the presence of a cotransport system and a $\mathrm{H}^{+}$pump in the MTs of Formica polyctena (Hymenopera, Formicidae). ${ }^{50-54}$ The presence of active and passive $\mathrm{K}^{+}$uptake mechanisms across the basal membrane was investigated in different bath $\mathrm{K}^{+}$concentrations. The authors proposed a model in which $\mathrm{K}^{+}$channels play a dominant role in high- $\mathrm{K}^{+}$bathing medium, and the results obtained from intracellular and luminal ion-selective measurements have demonstrated that the calculated gradients for $\mathrm{Cl}_{2}$ and $\mathrm{K}^{+}$are consistent with the transport mechanisms. ${ }^{55}$

The regulation of epithelial transport is mediated by intrinsic mechanisms and through messengers circulating in the hemolymph because MTs are not innervated. The triatomine Rhodnius prolixus (Hemiptera, Triatominae) has an abdomen sensed by stretch receptors in the abdominal cuticle that distend when it feeds on blood. This process triggers the release of serotonin and an unidentified peptide from several neurons, including from the central nervous system, mesothoracic ganglia, and the corpora cardiaca. ${ }^{56}$ 
Drosophila and mosquitoes have MTs with large and small cell types. The large cells are the principal cells, which are responsible for most of the mass of the tubule. The small cells are thin stellate cells. The principal cells mediate transepithelial secretion of $\mathrm{Na}^{+}$and $\mathrm{K}^{+}$, while the stellate cells and the paracellular transport pathway secrete $\mathrm{Cl}^{-}$. To power transepithelial transport, most vertebrate epithelia rely on the $\mathrm{Na} / \mathrm{K}$ ATPase, while MTs use the V-type $\mathrm{H}^{+}$-ATPase. The movement of water across the MTs occurs by both transcellular and paracellular pathways. ${ }^{11}$ Transcellular routes are the most actively studied, with a focus on aquaporin water channels that have been identified in all animal taxa. ${ }^{57}$

In Drosophila MTs, a multipotent stem cell was identified that is able to generate all cell types of the adult. In the same study, they found that autocrine JAK/STAT regulates stem cell self-renewal or differentiation. The methodology applied involved using heat shock to induce a mitotic genetic recombination event that leads to permanent expression of transgenes, like GFP (green fluorescent protein) or lacZ ( $\beta$-galactosidase) in a proliferating cell as well as in all progeny of that cell. Therefore, different molecular markers and clonal analysis bioassays showed that these cells are able to proliferate and differentiate into several types of cells. ${ }^{58}$

\section{Control}

Insects are an extremely ancient grouping of organisms with short life spans and, frequently, multiple generations per year that inhabit a wide variety of environmental niches. Because of this, the mechanisms of homeostasis control may show considerable variation between genera, even though the basic underlying themes are conserved. ${ }^{59}$

Insects are vulnerable to desiccation because of their small size and high surface area to volume ratio. Water can be obtained from the diet, but in order to maintain fluid homeostasis, it must equal the water lost through evaporation, respiration, and excretion. Excretory water loss is determined by the rate at which fluid enters the hindgut from the midgut and MTs, and the rate of reabsorption therein. ${ }^{60}$ Several substances play the role of regulation of ion homeostasis and fluid composition in MTs, which allows the insect to regulate hemolymph volume and composition. In the adult of Manduca sexta, for example, the stimulation of tubules is performed by biogenic amines (serotonin and octapamine), cyclic nucleotides (cGMP and cAMP), and peptides from three different classes (CAPs, leucokinins, TRPs). ${ }^{61}$ These compounds are hormones or neurohormones. They derive from the central nervous system (CNS) that exerts its control by means of neurohormones released into the extracellular fluid directly from the CNS, or other hormones from glands themselves controlled by the CNS hormones. For example, the TRPs are immunolabelling in brain neurons of $M$. sexta and also in midgut endocrine cells, ${ }^{61}$ which are the likely source of circulating TRPs that might act on the MTs. In addition to CNS, ion transport peptides (ITP) are expressed in the peripheral nervous system of Drosophila, specifically in hindgut-innervating abdominal ITP neurons. ${ }^{62}$

Diuretic hormones (DHs) and antidiuretic hormones (ADHs) are endocrine factors that affect the regulation of fluid excretion. These hormones consist of a diverse group of peptides that are produced by neurosecretory cells in the brain and ventral nerve cord ganglia. ${ }^{39}$ Water loss by excretion in insects is determined by the rate at which each fluid reaches the hindgut and midgut from the MTs and the reabsorption rate. Despite its name, usually, DHs stimulate the secretion of primary urine by MTs, and ADHs (aldosterone and vasopressin) increase the reabsorption of fluid from the hindgut. Primary urine formation must be driven by active transport, not by blood pressure. Since insects have low pressure circulatory systems, primary urine isosmotic to the hemolymph is secreted by the MTs. ${ }^{59}$ In the excretory process of insects, MTs generate a flow of primary urine that is subsequently modified by a reabsorptive and secretory process in the hindgut. Generally, DHs increase MT secretion by stimulating ion transport into the lumen accompanied by osmotically obliged water (osmotic filtration), which will either reduce MTs secretion or stimulate fluid and vital solute reabsorption in the hindgut. There are exceptions to the function of DHs, and sometimes their names do not precisely describe their actions. ${ }^{63}$

A multiplicity of peptides regulate diuresis and antidiuresis in insects: CRF-like DH, calcitonin (CT)-like DH, kinins, CAP2b, arginine vasopressin-like insect DH, serotonin and other biogenic amines, other peptides with diuretic activity, antidiuretic factor (ADFs), and ITP. The first of these factors to be identified that inhibits MT secretion, Tenmo-ADFa, was isolated from the pupal heads of $T$ enebrio molitor, based on its ability to elevate cyclic GMP (cGMP) levels in MTs of this species. ${ }^{64}$

The main transport through membrane is the sodiumpotassium pump that maintains the sodium gradient with energy required from ATP. To maintain the gradient of extracellular fluid, $\mathrm{Na}^{+}$is removed from the cell in exchange for $\mathrm{K}^{+}$. In the absence of ATP, or if the pump is poisoned by metabolic inhibitors, sodium leaks into the cell, and the sodium gradient disappears. Without the potential energy stored in the 
sodium gradient, indirect active transport processes such as the sodium-glucose cotransporter are unable to function. ${ }^{29}$

\section{Other functions}

In bumblebee Bombus atratus, a histochemical analysis of MT identified a mucous secretion produced by this organ. ${ }^{65}$ A similar study performed in the stingless bees Plebeia droryana and Scaptotrigona postica showed the participation of the mucous secretion produced by MTs in cocoon composition. ${ }^{65,66}$

The Malpighi tubules of the giant mealworm Zophobas morio (Coleoptera, Tenebrionidae) show a short antimicrobial peptides (AMP)-ligase with weak luciferase activity that diverged long ago from beetle luciferases ${ }^{67}$ These protoluciferases have an evolutionary importance in the investigation of bioluminescence origin in beetles.

Malpighian tubules of Drosophila melanogaster, in addition to their excretory function, act as autonomous immune sensing organs because their cells secrete AMP in response to invading microbial pathogens. The AMPs (diptericin, cecropin A, drosocin, and attacin A) are constitutively expressed and are regulated in a developmental stage-specific manner. ${ }^{68}$

The MTs of insects are also known to have mechanisms of active transport to remove toxic compounds such as alkaloids from vegetal sources ${ }^{8}$ and chemical compounds that are present in the environment and are toxic for insects. ${ }^{69}$

In addition to the obvious importance of the excretory system, the MTs have been widely used in ecotoxicological studies, as they quickly respond to changes in the insect's environment, and the tubules also induce detoxification genes, notably cytochrome P450s and glutathione $S$-transferases. ${ }^{70}$ This highlights the importance of understanding their structure and physiology. ${ }^{69,71-73}$

Different functions of MTs have emerged with the development of postgenomic technologies, mainly in Drosophila, such as microarrays, proteomics, and metabolomics. ${ }^{74}$ By means of molecular techniques, Chahine and O'Donnel175 suggest a coordinated response by the MTs, involving both alterations in detoxification pathways as well as enhanced fluid transport.

Molecular studies are revealing the mechanisms and modulation of the cell signaling in the MT that are related to stress tolerance in insects. ${ }^{76}$ The gene encoding Cytochrome P450-4e3 (Cyp4e3) is upregulated in the principal cells of the MT in Drosophila fed on permethrin. ${ }^{77}$ In MT of Drosophila, studies at the molecular level indicated the overexpression of a Cytochrome P450 gene, Cyp6gl, which has been evolved to insecticide resistance. ${ }^{78}$
Catae et $\mathrm{al}^{79}$ studied the effects of thiamethoxam in the midgut and MTs of the Apis mellifera honeybee. This study showed cellular responses of MTs after the commitment of the midgut induced by exposure to this neonicotinoid. ${ }^{50}$ Another study also showed that very low concentrations of imidacloprid lead to cytotoxic responses in the MTs of insecticide-exposed bees, implying that this effect can alter the ionic and fluid homeostasis in honeybee. ${ }^{80}$

\section{Closing arguments}

Although they were described for the first time in the 17th century and despite their apparent simple morphological organization, the MTs are key organs, performing different functions at different stages of development. In view of their importance for the maintenance of the individual homeostasis, and multiple assigned functions, many researchers are still devoted to studies of the MTs, and this review in no way exhausts the subject.

Recently, the understanding of transepithelial transport in insect MTs and its regulation processes has advanced considerably. The most important discoveries to illustrate this progress have been the isolation and sequencing of diuretic and antidiuretic peptides, the discovery of the V-type $\mathrm{H}^{+}$-ATPase as an energizer of plasma membranes, and the studies of epithelial transport functions using modern experimental methods. ${ }^{11,27}$

Genomic and proteomic analysis studies may elucidate their intracellular signaling mechanisms, ${ }^{81,82}$ regulating the immune response, ${ }^{83}$ in addition to other functions of MTs, as their relationship with the bioluminescence mechanism in some insects. ${ }^{84,85}$

The results indicate that MTs can be used for the evaluation of biomarkers, at the cellular level, in toxicological studies, especially studies done with sublethal doses and concentrations of chemicals. The various roles played by MTs reflect the interactions that organisms have with the environment in which they live. The different habitats of various organisms that have MTs as excretory system reflect the plasticity presented by this organ, and it may have many other functions too that have not been described. We can expect in the coming years, in light of the new techniques available and the development of the omic-sciences (transcriptomics, proteomics, and metabolomics), that new data will further elucidate the different mechanisms by which MTs perform their functions.

\section{Acknowledgment}

This study was supported by FAPESP 2012/50.197-2.

\section{Disclosure}

The authors report no conflicts of interest in this work. 


\section{References}

1. Snodgrass RE. Principles of insect morphology. New York: McGraw- Hill Book, 1956.

2. Borror DJ, Delong DM. Study of Insects. São Paulo, Ed. Edgard Blucha, 1969. Portuguese.

3. Wigglesworth, VB. The principles of insect physiology. New York: John Wiley Sons. 2003.

4. Wang J, Kean L, Yang J, Allan A K, Davies S A, Herzyk P, Dow JAT. Function-informed transcriptome analysis of Drosophila renal tubule. Genome Biol. 2004;5:69.

5. Maddrell SHP. The fastest fluid-secreting cell known: the upper Malpighian tubule cell of Rhodnius. BioEssays. 1991;13:357-362.

6. Jung AC, Denholm B, Skaer H, Affolter M. Renal tubule development in Drosophila: a closer look at the cellular level. J Am Soc Nephrol. 2005; 16:322-328.

7. Singh SR, Hou SX. Lessons Learned About Adult Kidney Stem Cells From the Malpighian Tubules of Drosophila. J Am Soc Nephrol. 2008;19:660-666.

8. Chapman RF. The insects: Structure and function. Fourth Ed. Cambridge University Press, Cambridge, 1998.

9. Bradley TJ. The excretory system: structure and physiology. In: Kerkut, GA, Gilbert, LI (Eds.) Comprehensive Insect Physiology, Biochemistry and Pharmacology, vol. 4, Pergamon Press, London, pp. 421-465, 1985.

10. Arab A, Caetano FH. Segmental specializations in the Malpighian tubules of the fire ant Solenopsis saevissima Forel 1904 (Myrmicinae): an electron microscopical study. Arthropod Struct Dev. 2002;30: 281-292.

11. Beyenbach KW, Skaer H, Dow JAT. The Developmental, Molecular, and Transport Biology of Malpighian Tubules. Annu Rev Entomol. 2010;55:351-374.

12. Jung AC, Denholm B, Skaer H, Affolter M. Renal tubule development in Drosophila: a closer look at the cellular level. J Am Soc Nephrol. 2005;16(2):322-328.

13. Cruz-Landim C. Morfology and function of systems. 1ed. São Paulo: UNESP, 2009. Portuguese.

14. Cruz-Landim C, Rodrigues L. Development of rectal glands and Malpighian Tubules in bess from the genera Melipona, with relation to the humidity of their natural habitat. Ciência e Cultura. 1970;23:619-623. Portuguese.

15. Silva-de-Moraes RLM, Cruz-Landim C. Comparative studies of Malpighian tubules from larvae, pupae and adults workers of Melipona quadrifasciata anthidioides Lep. (Apidae, Meliponinae). Papéis Avulsos de Zoologia 29, 1976;249-257. Portuguese.

16. Cruz-Landim C. Localization of calcium and acid phosphatase in the Malpighian tubules of nurse workers of Melipona quadrifasciata anthidioides Lep. (Hymenoptera, Apidae, Meliponini). Biosci J. 2000;16:87-99.

17. Skaer HB. Development of the alimentary canal. In The Development of Drosophila, ed. CM Bate, A Martinez Arias, pp. 941-1012. Cold Spring Harbor, NY: Cold Spring Harbor Lab. Press.1993.

18. Tapadia MG, Gautam NK. Non-apoptotic function of apoptotic proteins in the development of Malpighian tubules of Drosophila melanogaster. J Biosci Bangalore. 2011;36(3):531-544.

19. Ettershank G, Brown WL. The Malpighian tubules as meristic characters in ants (Hym., Formicidae). Entomologist's Monthly magazine. 1964;100:5-7.

20. Caetano FH, Camargo-Mathias MI, Overal WL. Anatomy and histology of digestory tract from Dinoponera gigantea and Paraponera clavata (Formicidae: Ponerinae). Naturalia. 1986/1987;11/12:125-134. Portuguese.

21. Bution ML, Caetano FH, Zara FJ. Contribution of the Malpighian tubules for the maintenance of symbiotic microorganisms in Cephalotes ants Micron. 2008;39:1179-1183.

22. Arab A, Caetano FH. Segmental specializations in the Malpighian tubules of the fire ant Solenopsis saevissima Forel 1904 (Myrmicinae): an electron microscopical study. Arthropod Struc Develop. 2002;30: 281-292.
23. Gonçalves WG, Fialho MDCQ, Azevedo DO, Zanuncio JC, Serrão, JE. Ultrastructure of the excretory organs of Bombus morio (Hymenoptera: Bombini): bee without rectal pads. Microscopy and Microanalysis. 2014;20(01):285-295.

24. Sohal RS. Fine structure of the Malpighian tubules in the house fly Musca domestica. Tissue Cell. 1974;6:719-728.

25. Dallai R, Del Bene G, Marchini D. The ultrastructure of Malpighian tubules and hindgut of Frankliniella occidentalis (pergande) (Thysanoptera: Thripidae). Int J Insect Morphol. 1991;20: 223-233.

26. Ryerse JS. Ecdysterone switches off fluid secretion at pupation in insect Malpighian tubules. Nature. 1978;271:745-748.

27. Beyenbach KW Transport mechanisms of diuresis in Malpighian tubules of insects. J Exp Biol. 2003;206:3845-3856.

28. Caetano FH, Cruz-Landim C. Ultrastructure of columnar cells from ventricle of Camponotus arboreus (Hymenoptera: Formicidae) and their functional implications. Naturalia. 1983;8:91-100. Portuguese.

29. Silverthorn DU. Active Transport in Insect Malpighian Tubules, in: Goldman CA, Editor. Tested studies for laboratory teaching. 1995; 16:141-154, .

30. Cruz-Landim C. Specializations of the Malpighian Tubules cells in a stingless bee, Melipona quadrifasciata anthidioides Lep. (Hymenoptera, Apidae). Acta Microscopica. 1988;7:26-33.

31. Scholes DR, Suarez AV, Smith AA, Johnston JS, Paige KN. Organspecific patterns of endopolyploidy in the giant ant Dinoponera australis. J Hymenop Res. 2014;37:113-126.

32. Rangel J, Strauss K, Seedorf K, Hjelmen CE, Johnston JS. Endopolyploidy Changes with Age-Related Polyethism in the Honey Bee, Apis mellifera. PloS one. 2015;10(4).

33. Wall BJ, Oschman JL, Schmidt BA. Morphology and function of Malpighian tubules and associated structures in the cockroach Periplaneta americana. J. Morph. 1975;146:265-306.

34. Wigglesworth VB, Salpeter MM. Histology of the Malpighian tubules in Rhodnius prolixus Stil (Hemiptera). Insect Physiol. 1962;8: 299-307.

35. Maddrell SHP,Herman WS, Mooney RL, Overton JA. 5-hydroxytryptamine: a second diuretic hormone in Rhodnius prolixus. J Exp Biol. 1991;156:557-566.

36. Delakorda SL, Letofsky-Papst I, Novak T, Hofer F, Pabst MA. Structure of the Malpighian Tubule Cells and Annual Changes in the Structure and Chemical Composition of Their Spherites in the Cave Cricket Troglophilus neglectus Krauss, 1878 (Rhaphidophoridae, Saltatoria). Arthropod Struct Dev. 2009;38:315-327.

37. Bution ML, Caetano FH, Zara FJ. Comparative morphology of the ileum of three species of Cephalotes (Formicidae, Myrmicinae). Sociobiol. 2007;50:355-369.

38. Wang J, Kean L, Yang J, Allan AK, Davies SA, Herzyk P, Dow JA. Function-informed transcriptome analysis of Drosophila renal tubule. Genome Biol. 2004;5(9):R69.

39. Catania VA, Sanchez Pozzi EJ, Luquita MG, et al. Co-regulation of expression of phase II metabolizing enzymes and multidrug resistanceassociated protein 2. Ann Hepatol. 2004;3:11-17.

40. Enayati AA, Ranson H, Hemingway J. Insect glutathione transferases and insecticide resistance. Insect Mol Biol. 2005;14:3-8.

41. Beyenbach KW. Mechanism and regulation of electrolyte transport in Malpighian tubules. J Insect Physiol. 1995;41:197-207.

42. Linton SM, O'Donnell MJO. Novel aspects of the transport of organic anions by the Malpighian tubules of Drosophila melanogaster. J Exp Biol. 2000;203:3575-3384.

43. Marshall AT, Cooper P, Rippon GD, Patak AE. Ion and fluid secretion by different segments of the Malpighian tubules of the black field cricket Teleogryllus oceanicus. J Exp Biol. 1993;177:1-22.

44. O’Donnell MJ, Maddrell SHP. Fluid reabsorption and ion transport by the lower Malpighian tubules of adult female Drosophila. J Exp Biol. 1995;198:1647-1653.

45. Van Kerkhove E. Cellular mechanisms of salt secretion by the Malpighian tubules of insects. Belg J Zool. 1994;124:73-90. 
46. Coast GM. The neuroendocrine regulation of salt and water balance in insects. Zoology. 2001;103:179-188.

47. Spring JH, Albarwani SA. Excretion in the house cricket: stimulation of rectal reabsorption by homogenates of the corpus cardiacum. $J$ Exp Biol. 1993;185:305-323.

48. Berrigde MJ, Oschman JL. A structural basis for fluid secretion by Malpighian tubules. Tissue Cell. 1969;1:247-272.

49. Beyenbach KW. Energizing epithelial transport with the vacuolar H+-ATPase. News Physiol Sci. 2001;16:145-151.

50. Verhulst H, Van Kerkhove E, De Decker N. KCl secretion by Malpighian tubules of Formica: evidence for the presence of a $\mathrm{KCl}$ cotransport system. Archs int Physiol Biochem. 1988;96:P8-P9.

51. Weltens R, Leyssens A, Zhang AL, Lohrmann E, Steels P, Van Kerkhove E. Unmasking of the apical electrogenic $\mathrm{H}+$ pump in isolated Malpighian tubules (Formica polyctena) by the use of barium. Cell Physiol Biochem. 1992;2:101-116.

52. Leyssens A, Steels P, Lohrmann E, Weltens R, Van Kerkhove E. Intrinsic regulation of $\mathrm{K}+$ transport in Malpighian tubules (Formica): electrophysiological evidence. J Insect Physiol. 1992;38:431-446.

53. Leyssens A, Zhang SL, Van Kerkhove E, Steels P. Both dinitrophenol and $\mathrm{Ba} 2+$ reduce $\mathrm{KCl}$ and fluid secretion in Malpighian tubules of Formica: the role of the apical $\mathrm{H}+$ and $\mathrm{K}+$ concentration gradient. J Insect Physiol. 1993;39:1061-1073.

54. Leyssens A, Van Kerkhove E, Zhang SL, Weltens R, Steels P. Measurement of intracellular and luminal $\mathrm{K}+$ concentrations in a Malpighian tubule (Formica): estimates of basal and luminal electrochemical gradients. J Insect Physiol. 1993;39:945-958.

55. Leyssens A, Dijkstra S, Van Kerkhove E, Steels P. Mechanisms of $\mathrm{K}+$ uptake across the basal membrane of Malpighian tubules of Formica polyctena: the effect of ions and inhibitors. $J$ Exp Biol. 1994;195:123-145.

56. Chiang RG, Davey KG. A novel receptor capable of monitoring applied pressure in the abdomen of an insect. Science. 1988;241:1665-1667.

57. Kawedia JD, Nieman ML, Boivin GP, et al. Interaction between transcellular and paracellular water transport pathways through Aquaporin 5 and the tight junction complex. Proc Natl Acad Sci U S A. 2007;104:3621-3626.

58. Singh SR, Hou SX. Multipotent stem cells in the Malpighian tubules of adult Drosophila melanogaster. J Exp Biol. 2009;212:413-423.

59. Schooley DA, Horodyski FM, Coast GM. Hormones controlling homeostasis in insects: endocrinology. In: Gilbert LI, Iatrou K, Gill S, editors. Comprehensive Molecular Insect Science. Vol. 3. Amsterdam: Elsevier;2005.

60. Gibbs AG, Chippindale AK, Rose MR. Physiological mechanisms of evolved desiccation resistance in Drosophila melanogaster.J Exp Biol. 1997;200:1821-1832.

61. Skaer NJV, Nässel DR, Maddrell SHP, Tublitz NJ. Neurochemical fine tuning of a peripheral tissue: peptidergic and aminergic regulation of fluid secretion by Malpighian tubules in the tobacco hawkmoth Manduca sexta. J Exp Biol. 2002;205:1869-1880.

62. Dircksen $H$. Insect ion transport peptides are derived from alternatively spliced genes and differentially expressed in the central and peripheral nervous system. $J$ Exp Biol. 2009;212:401-412.

63. Phillips JE. Endocrine control of salt and water balance. Excretion. In Endocrinology of Insects (ed. H. Laufer and R. Downer), pp. 411-425. New York: Alan R. Liss, 1983.

64. Kastin AJ. (Ed.). The Handbook of Biologically Active Peptides. Elsevier, Amsterdam, 2006.

65. Mello ML. A mucous secretion in the Malphighian tubes of a neotropical bumblebee, Bombus atratus Franklin. Protoplasma. 1979;99:147-158.

66. Mello ML, Kerr WE. Histochemistry of salivary gland and Malpighian tubule secretions contribuiting to the cocoon in Plebeia droryana and Scaptotrigona postica (Hym., Apoidea). Zool Anz Jena. 1984;213:177-189.

67. Viviani VR, Prado RA, Arnoldi FCG, Abdalla, FC. An ancestral luciferase in the Malpighi tubules of a non-bioluminescent beetle!. Photochemical and Photobiological Sciences. 2009;8(1):57-61.
68. Verma P, Tapadia MG. Immune response and anti-microbial peptides expression in Malpighian tubules of Drosophila melanogaster is under developmental regulation. PLoS One, 2012;7(7):e40714. doi: 10.1371/ journal.pone.0040714. Erratum in: PLoS One. 2012;7(8). doi: 10.1371/ annotation/4b02305d-dcb8-40db-8f1f-1f7f0da51544

69. Sorour J. Ultrastructural variations in Lethocerus niloticum (Insecta: Hemiptera) caused by pollution in Lake Mariut, Alexandria, Egypt Ecotox Environ Safe. 2001;48:268-274.

70. Yang J, McCart C, Woods DJ, Terhzaz S, Greenwood KG, et al. A Drosophila systems approach to xenobiotic metabolism. Physiol Genomics. 2007;30:223-231.

71. Malaspina O, Silva-Zacarin, ECM. Cell markers for ecotoxicological studies in target organs of bees. Braz J Morphol Sci. 2006;23(3-4):129-136.

72. Sumida S, Silva-Zacarin ECM, Decio P, Malaspina O, Bueno FC, Bueno OC. Toxicological and histopathological effects of boric acid on Atta sexdens rubropilosa (Hymenoptera: Formicidae) workers. $J$ Econ Entomol. 2010;103(3):676-690.

73. Decio P, Silva-Zacarin ECM, Bueno FC, Bueno OC. Toxicological and histopathological effects of hydramethylnon on Atta sexdens rubropilosa (Hymenoptera: Formicidae) workers. Micron. 2013;45: 22-31.

74. Dow JAT. Insights into the Malpighian tubule from functional genomics. The Journal of Experimental Biology. 2009;212:435-445.

75. Chahine S, O'Donnell MJ. Interactions between detoxification mechanisms and excretion in Malpighian tubules of Drosophila melanogaster. J Exp Biol. 2011;214(Pt 3):462-8. doi: 10.1242/jeb.048884.

76. Davies SA, Cabrero P, Overend G, et al. Cell signalling mechanisms for insect stress tolerance. $J$ Exp Biol. 2014;217 (Pt 1):119-28. doi: 10.1242/jeb.090571.

77. Terhzaz S, Cabrero P, Brinzer RA, et al. A novel role of Drosophila cytochrome $\mathrm{P} 450-4 \mathrm{e} 3$ in permethrin insecticide tolerance. Insect Biochem Mol Biol. doi: 10.1016/j.ibmb.2015.06.002.

78. Harrop TW, Sztal T, Lumb C, et al. Evolutionary changes in gene expression, coding sequence and copy-number at the Cyp6g1 locus contribute to resistance to multiple insecticides in Drosophila. PLoS One. 2014;9(1):e84879. doi: 10.1371/journal.pone.0084879. Erratum in: PLoS One. 2014;9(3):e92490.

79. Catae AF, Roat TC, De Oliveira RA, Ferreira Nocelli RC, Malaspina O. Cytotoxic effects of thiamethoxam in the midgut and Malpighian Tubules of Africanized Apis mellifera (Hymenoptera: Apidae). Microsc Res Tech. 2014;77:274-281.

80. Rossi CA, Roat TC, Tavares DA, Cintra-Socolowski P, Malaspina O. Effects of sublethal doses of imidacloprid in Malpighian tubules of Africanized Apis mellifera (Hymenoptera, Apidae). Microsc Res Tech. 2013;76(5):552-558.

81. Pannabecker TL, Beyenbach KW. Ca2+ and cAMP signaling pathways interact to increase the diuretic effect of serotonin in Malpighian tubules of the kissing bug. Focus on" Serotonin triggers cAMP-and PKA-1mediated intracellular calcium waves in Malpighian tubules of Rhodnius prolixus. Am J Physiol-Reg I. 2014;37(7):819-821.

82. Gioino P, Murray BG, Ianowski JP. Serotonin triggers cAMP and PKAmediated intracellular calcium waves in Malpighian tubules of Rhodnius prolixus. Am J Physiol-Reg I.2014;307(7):828-836.

83. Verma P, Tapadia MG. Early gene Broad complex plays a key role in regulating the immune response triggered by ecdysone in the Malpighian tubules of Drosophila melanogaster. Mol immunol. 2015;66.2:325-339.

84. Silva JR, Prado RA, Amaral DT, Viviani VR. First transcriptional survey of the Malpighian tubules of giant mealworm, Zophobas morio (Coleoptera: Tenebrionidae).Genet Mol Res. 2015a;1:464.

85. Silva JR, Amaral DT, Hastings JW, Wilson T, Viviani VR. A transcriptional and proteomic survey of Arachnocampa luminosa (Diptera: Keroplatidae) lanterns gives insights into the origin of bioluminescence from the Malpighian tubules in Diptera. Luminescence. 2015b; DOI $10.1002 /$ bio. 2850 
Open Access Insect Physiology

\section{Publish your work in this journal}

Open Access Insect Physiology is an international, peer-reviewed, open access journal publishing original research, reports, reviews and commentaries on all areas of insect physiology. The manuscript management system is completely online and includes a very quick and fair peer-review system, which is all easy to use.

Submit your manuscript here: http://www.dovepress.com/open-access-insect-physiology-journal 